\title{
Stress and Burnout among multidisciplinary residents
}

\author{
Laura de Azevedo Guido \\ Carolina Tonini Goulart² \\ Rodrigo Marques da Silva ${ }^{3}$ \\ Luis Felipe Dias Lopes ${ }^{1}$ \\ Emanuelli Mancio Ferreira ${ }^{4}$
}

Objective: To identify associations between high-stress and burnout syndrome in multidisciplinary residents from a federal university in Rio Grande do Sul, Brazil. Method: This is an analytical, cross-sectional and quantitative study. A socio-demographic questionnaire, the Work Stress Scale and the Maslach Burnout Inventory-Health Services Survey (MBI-HSS) were applied to 37 residents between April and June 2011. P-values<0.05 were considered statistically significant. Results: We verified that $48.65 \%$ of the residents experienced high-stress. When associating the MBI-HSS subscales, we verified that $27 \%$ of the residents showed some indication of burnout syndrome. There was a statistically significant correlation $(p=0.00, r=0.68)$ between a highstress and burnout. Conclusions: High-stress was confirmed as being a predictor of burnout syndrome among multidisciplinary residents. Therefore, we propose that intervention studies be conducted in order to change such contexts.

Descriptors: Nursing; Burnout, Professional; Internship, Nonmedical; Inservice Training; Analytical Epidemiology.

${ }^{1}$ PhD, Associate Professor, Universidade Federal de Santa Maria, Brazil.

2 RN, Master's Student, Universidade Federal de Santa Maria, Brazil.

${ }^{3}$ RN, Master's Student, Universidade Federal de Santa Maria, Brazil.

${ }^{4}$ Undergraduate student in Nursing, Universidade Federal de Santa Maria, Brazil. Bolsista do Scholarship holder of the Scientific Initiation Program (PIBIC) at the Conselho Nacional de Desenvolvimento Científico e Tecnológico (CNPq), Process \# 800003/2011-0. 


\section{Estresse e Burnout entre residentes multiprofissionais}

Objetivo: identificar a associação entre alto estresse e Burnout em residentes multiprofissionais de uma universidade federal do Rio Grande do Sul. Método: trata-se de estudo analítico, transversal, quantitativo. Aplicaram-se um formulário de dados socio demográficos, a Escala de Estresse no Trabalho e o Maslach Burnout Inventory-Human Services Survey (MBI-HSS) em 37 residentes entre abril e junho de 2011. Valores de $p<0,05$ foram considerados estatisticamente significativos. Resultados: verificou-se que $48,65 \%$ de residentes apresentavam alto estresse. $\mathrm{Na}$ associação das subescalas do MBI, $27 \%$ dos residentes apresentaram indicativo para síndrome de Burnout. Observou-se correlação estatisticamente significativa $(p=0,00 ; r=0,68)$ entre alto estresse e Burnout. Conclusões: confirmou-se o alto estresse como preditor da síndrome de Burnout entre os residentes multiprofissionais. Assim, propõe-se a realização de estudos com delineamento interventivo para que essa realidade seja modificada.

Descritores: Enfermagem; Esgotamento Profissional; Internato não Médico; Capacitação em Serviço; Epidemiologia Analítica.

\section{Estrés y Burnout entre residentes multiprofesionales}

Objetivo: Identificar la asociación entre alto estrés y Burnout en residentes Multiprofesionales de una universidad federal de Rio Grande do Sul. Método: se trata de un estudio analítico, transversal, cuantitativo. Se aplicaron un formulario de datos socio-demográficos, la Escala de Estrés en el Trabajo y el Maslach Burnout Inventory- Health Services en 37 residentes entre Abril y Junio de 2011. Valores de $p<0,05$ fueron considerados estadísticamente significativos. Resultados: se verificó $48,65 \%$ de residentes en alto estrés. En la asociación de las subescalas del MBI, 27\% de los residentes presentaron indicativo para Síndrome de Burnout. Se observó correlación estadísticamente significativa $(p=0,00 ; r=0,68)$ entre alto estrés y Burnout. Conclusiones: se confirmó el alto estrés como predictor del Síndrome de Burnout entre los residentes multiprofesionales. Así, se propone la realización de estudios con delineamiento de intervención para que esa realidad sea modificada.

Descriptores: Enfermería; Agotamiento Profesional; Internado no Médico; Capacitación en Servicio; Epidemiología Analítica.

\section{Introduction}

The industrial revolution that took place in the $18^{\text {th }}$ and $19^{\text {th }}$ centuries was characterized by remarkable economic development and marked by the displacement of individuals from rural areas to the factories' cities, which led to important changes in the life conditions of workers. However, poverty, prolonged and fatiguing working hours, poor diet and appalling living conditions continued to afflict the working class ${ }^{(1)}$.

At the same time, progress in science also led to organizational and technological innovations transforming the activities of workers, especially those in the health field(2). Therefore, discussions concerning the health of workers and its relationship with the work environment stand out.

In this context, stress has been highlighted, which according to the interactionist model, is defined as any stimulus that makes demands of the external or internal environment and taxes or exceeds the adaptive sources of an individual or social system(3).

According to this model, a cognitive evaluation takes place, that is, a mental process in which one locates the event or situation in a series of evaluative categories that are related to the person's representation of wellbeing(3). In this process, the individual initially identifies the demands of a situation and defines the meaning of such an event (primary evaluation). If the event is defined as a threat or challenge, there is a reaction to stress and the possibility of coping strategies and/or adaptation to the stressful event is verified (secondary evaluation) ${ }^{(3)}$.

If these strategies are not used or if they fail, the stressor remains and stress may become chronic and lead to Burnout Syndrome ${ }^{(4)}$. Burnout is seen as a process that takes place in response to chronic stress, 
negatively affecting individuals as professionals, family members and social beings ${ }^{(4)}$.

Burnout in the health field is linked to the work process. There are, however, situations and activities in the educational process, both in undergraduate and graduate programs, that can be seen as stressors, especially those related to educational and professional practice.

In this context, Multidisciplinary Residency Programs (MRP) in the health field, regulated as non-degree programs, seek to break with paradigms in relation to the education of professionals preparing for the Brazilian Unified Health System, (SUS) and contribute to the qualification of health services offered to the population. They present a variety of methodological designs but all defend the use of active and participatory methodologies and continuous education as the pedagogical axis(5).

Additionally, their intrinsic interdisciplinary nature confers an innovative character to the programs, which is mainly shown through the inclusion of 14 professions in the field of health. This way of proceeding with 'intercategories' aims for collective education included in the same 'field' of practice in relation to the specific 'cores' of knowledge of each profession ${ }^{(5-6)}$.

The multidisciplinary residency program in the studied institution began in 2009 and was offered for the following professions: Nursing, Psychology, Nutrition, Social Work, Physical Therapy, Speech Therapy, Pharmacology, Occupational Therapy, and Dentistry. Physical Education was included in 2010(6).

In the first year the program was financed by the Ministry of Health and focused on three concentrations: Health Management and Policies, Family Primary Health Care, and Hospital Care. In 2010, the Ministry of Education and Culture (MEC) started financing residency programs in university hospitals and the original program was divided into two concentrations. Hence the program linked to the Ministry of Health was then composed by: Family Primary Health Care and Health Surveillance. Hospital Management and Care was then linked to and financed by $\operatorname{MEC}^{(6)}$.

Given this context, in which we observe the philosophy of the educational process in the health field with innovative actions, some aspects can be seen as stressors, especially because they are not included in the traditional educational model. Among them, the following stand out: teamwork, active and participatory methodologies, interpersonal relationships established with other professionals, and the responsibility to deliver integral and humanized care.
Stress can be also associated with potential liability for treatments, the treatment of severe patients, administration of problems, management of the volume of knowledge, and the establishment of limits to one's personal and professional identity ${ }^{(7)}$. Additionally, it may result from the training characteristics, such as sleep deprivation, fatigue, heavy workload, excess administrative work, problems related to the quality of education and the educational environment( ${ }^{(7)}$. Individual characteristics and personal contexts, such as gender, personality, and psychological vulnerabilities can also be related to stress $^{(7)}$.

Studies $^{(1,3)}$ have investigated stress among workers from different professions in the health field, especially nurses. This profession has been considered stressful due to its peculiarities in the development of the work process. Among them are: the need for nurses in health services 24 hours a day, the need to mediate relationships and needs among patients, nursing technicians and other professionals in the multidisciplinary team, and the need to perform managerial activities concomitantly with care delivery. For the same reason, burnout syndrome has been observed in diverse types of individuals, including both medical( $^{(8)}$ and nursing(9) residents. This study, however, addresses burnout syndrome and its relationship with high-stress among different professions and, therefore, evaluates this subject considering the relationship of nurses with the remaining professionals on staff. Thus, we defend the hypothesis that residents with high-stress present indications of burnout syndrome.

Given the preceding discussion, this study's objective was to identify the association between highstress and burnout in multidisciplinary residents from a federal university in the center of Rio Grande do Sul, Brazil.

\section{Method}

This is an analytical, cross-sectional and quantitative study. The study was conducted in a federal university in the center of Rio Grande do Sul, Brazil. Residents whose concentrations were the Family Primary Health Care, Health Surveillance, and Hospital Management and Care of all professions included in the programs and regularly enrolled in the 2009, 2010 and 2011 classes were included in the study: Nursing, Psychology, Nutrition, Social Worker, Physical Therapy, Pharmacy, Occupational Therapy, Dentistry, and Physical Education. Those on any kind of leave were not included. There were 85 
multidisciplinary residents registered at the time of data collection. All met the inclusion criteria but 40 (47.06\%) refused to participate and eight $(9.41 \%)$ returned the instruments without filling them out, totaling 37 (43.53\%) participants.

Data were collected from April to June 2011 using the Work Stress Scale (WSS) ${ }^{(10)}$ and Maslach Burnout Inventory - Human Services Survey (MBI- HSS)(11). These instruments were applied to the participants who voluntarily agreed to participate in the study after being informed of the study's objectives and characteristics. They were initially invited to participate in meetings and those who did not attend the meetings were individually approached.

The WSS was constructed and validated in 2004(10). It is composed of 23 items distributed on a five-point Likert scale ranging from: 1 - strongly disagree, 2 - disagree, 3 - somewhat agree, 4 - agree, and 5 strongly agree. The sum of scores obtained in each item results in the total score for stress; the higher the score the higher the level of stress ${ }^{(10)}$.

The MBI-HSS was translated and adapted to Brazilian culture by Liana Lautert in $1995^{(11)}$. It is a self-applied questionnaire with a five-point Likert scale ranging from: 0 - never, 1 - a few times a year, 2 - a few times a month, 3 - a few times a week, 4 - daily. Thus, according to the individual's experience at work, the minimum value to assign is zero and the maximum value is four ${ }^{(11)}$. The instrument is composed of 22 items distributed into three subscales: Emotional Exhaustion (EE), composed of items 1, 2, 3, 6, 8, 13, 14, 16 and 20; Depersonalization (DP), composed of items 5, 10, 11, 15 and 22; and Professional Incompetence (PI), composed of items $4,7,9,12,17,18,19$ and $21^{(11)}$. However, the researcher ${ }^{(12)}$ notes that items and domains of the instruments should not contain preconceived judgments and should be obtained from data analysis. For this reason, the following denominations were used for the subscales: Emotional Exhaustion (EE), Depersonalization (DP), and Professional Realization (PR) ${ }^{(13)}$.

Emotional Exhaustion is characterized as emotional overload. It reflects the individuals' feelings concerning their job. It is the initial trait of burnout, marked by psychological and physical manifestations, with a reduced capacity for production. Depersonalization is the specific characteristic of the syndrome, defined as insensitivity and dehumanization in care practice and treating clients and colleagues with coldness and indifference. Low Professional Realization corresponds to low efficiency and productivity at work ${ }^{(9)}$. High scores in
Emotional Exhaustion and Depersonalization associated with a low score in Professional Realization indicate the individual is experiencing burnout ${ }^{(11)}$.

After collection, data were organized and stored in an electronic spreadsheet in Excel 2007 (Office XP) to be later analyzed through the Statistical Analysis System (SAS) version 8.02. The qualitative variables were presented in absolute ( $n$ ) and relative (\%) values and the quantitative variables in descriptive measures such as minimum and maximum values, average $(\bar{x})$ and standard deviation $( \pm)$. Pearson's correlation test was used to verify the relationship between stress and burnout. $\mathrm{P}<0.05$ was considered statistically significant with a Confidence Interval of $95 \%$.

The overall average was computed to analyze the WSS. Based on this information, the answers were divided into "high-stress" and "low-stress". In the case of the MBI-HSS, the sum of the scores assigned to each item was divided by the total number of items in the subscale, which resulted in an average per subscale. Then, based on this average, the subscales were divided into "high" and "low". Thus, values above the overall average obtained on the WSS and above the average obtained for each subscale of MBI-HSS were classified as "high-stress" and below these measures were considered to be "low-stress". Additionally, the classifications obtained by each individual in the three subscales of MBI-HSS were associated. Hence, when this association was concomitantly High Emotional Exhaustion, High Depersonalization and Low Professional Realization, the resident was considered to be experiencing burnout syndrome. Cronbach's Alpha Coefficient was used to analyze the instruments' internal consistency.

In order to meet the Brazilian National Health Council's guidelines and standards(14) as established for studies involving human subjects, the participants voluntarily consented to participate in the study by signing two copies of free and informed consent forms (one for the participant and another for the researcher), after being informed of the study's objectives. A term of confidentiality was also handed out, manifesting the researchers' commitment in using and preserving the material (within a period of five years) with information provided by the participants.

This study is part of the project Stress, Coping, Burnout, Depressive Symptoms and Hardiness in Medical and Multidisciplinary Residences, approved by the Ethics Research Committee at the University (protocol No. 23081.020160/2010-06). 


\section{Results}

The analysis of internal consistency of the items that compose the WSS presented a Cronbach's alpha of 0.91 . For the MBI-HSS, this coefficient was 0.82 for Emotional Exhaustion and 0.63 for Depersonalization. Since Cronbach's alpha for the subscale Professional Realization was 0.24 , items 9 and 21 were included in it and the coefficient increased to 0.60 . According to the authors $^{(3)}$, these values are sufficient to attest to the instrument's satisfactory internal reliability.

In relation to the WSS, $51.35 \%$ of the residents presented low-stress and $48.65 \%$ presented highstress. The descriptive measures for this instrument were: average of $2.80( \pm 0.69)$ and the minimum and maximum values were 22 and 71 , respectively.
In relation to the MBI-HSS, an average of 2.55 $( \pm 0.71)$ was observed for Emotional Exhaustion, $2.72( \pm 0.80)$ for Depersonalization and $3.42( \pm 0.73)$ for Professional Realization Additionally, we verified that $37.84 \%$ presented high averages in Emotional Exhaustion, $43.24 \%$ presented high averages in Depersonalization, and $48.65 \%$ presented low averages in Professional Realization. When the subscales were associated, $27 \%$ of the participants presented indications of experiencing burnout syndrome.

The correlations among the classifications of stress and the MBI-HSS subscales are presented in Table 1. A statistically significant positive correlation was observed between high-stress and burnout syndrome $(p=0.00$ $r=0.68)$.

Table 1 - Matrix of correlation between the classifications of stress and the MBI-HSS subscales in Multidisciplinary Residents, RS, Brazil, 2012

\begin{tabular}{lcccc}
\hline Classification of stress & Emotional Exhaustion & Depersonalization & Professional realization & $\mathbf{N}$ \\
\hline High & $r=0.80^{*}$ & $r=0.62^{*}$ & $r=-0.44$ & 18 \\
Low & $(p=0.00)$ & $(p=0.00)$ & $(p=0.06)$ & 19 \\
Total & $r=0.60^{*}$ & $r=0.65^{*}$ & $r=-0.28$ & 37 \\
\hline
\end{tabular}

*Significant correlation $(p<0.05)$

Given the study's hypothesis, data concerning lowstress will not be discussed.

\section{Discussion}

Multidisciplinary residents are included in a peculiar context because they are exposed to situations concerning both the work process and the learningteaching process, both of which may be considered stressful. A total of $51.35 \%$ of the participants presented low-stress and $48.65 \%$ presented high-stress. A study ${ }^{(3)}$ addressing nurses from a surgical ward reported that $55.56 \%$ of these professionals presented low-stress and $11.12 \%$ presented high-stress. A study ${ }^{(15)}$ conducted in a public hospital in South Africa reported that $46 \%$ of physicians presented low-stress and $27 \%$ presented high-stress.

The distribution of individuals experiencing highstress differs significantly among the studies $^{(3,15)}$. Even though such differences may be attributed to sampling differences, it may also be that the residents see stress differently regardless of being exposed to similar situations or situations typical to their profession.
It corroborates the statement that the evaluation of stressors is individual and involves cognitive, emotional and behavioral functions ${ }^{(4)}$.

We also know that when professionals perceive a situation as being stressful, they make an evaluation to find appropriate ways to cope with it, which may either solve or minimize the effects of stress ${ }^{(4)}$. In this sense, we observe the prevalence of low-stress in this study and in the others ${ }^{(3,15)}$ previously mentioned. It suggests that the professionals, including the residents, have used effective coping strategies to minimize occupational stress. In this context, a study analyzed the coping strategies used by nurses with and without indication of burnout syndrome and reported that problem-solving strategies help to prevent burnout ${ }^{(16)}$. Therefore, the use of ineffective coping strategies may favor stress becoming chronic among multidisciplinary residents and, consequently, lead to burnout syndrome.

We observed, when associating the MBI-HSS subscales, that $27 \%$ of the multidisciplinary residents presented an indication of burnout. A study ${ }^{(9)}$ with nursing residents investigated burnout syndrome in the four periods of residency and reported the presence 
of a professional (6.3\%) in the fourth period to be related with alterations in the three subscales and, consequently, with burnout syndrome. Another study(17) involving 12 European countries and the United States verified that $78 \%$ of the nurses in Greece and $42 \%$ of those in England presented burnout syndrome.

Stressors may be seen either as a threat or a challenge, but burnout syndrome is a negative situation and a risk to the worker's life ${ }^{(16)}$. Therefore, the consequences of the syndrome interfere in one's learning process and impact the quality of care provided by the residents to patients and their families. This is seen in a study ${ }^{(17)}$ reporting that the satisfaction of patients was lower in hospitals where nurses experienced burnout. A study addressing nurses of 168 hospitals in Pennsylvania, USA reports that each extra patient per nurse was associated with a $23 \%$ of increase in burnout syndrome, a $7 \%$ increase in the probability of death of patients in the period of 30 days after admission, and a $7 \%$ increase in the number of mistakes in care provided to individuals. Additionally, burnout syndrome affects the workplace since workers may have negative attitudes toward people and the organization, and one possible outcome is sick leave.

A study ${ }^{(18)}$ performed in the United States identified that $43 \%$ of nurses experiencing burnout intended to quit their jobs in the next 12 months. Another study(19) reported that nurses had on average of 1.71 days a year of sick leave and 3.86 days off a year. These data are related to diseases that result from occupational stress and may lead to burnout(20). In some cases, workers may keep working but experience health problems and reduced productivity; this situation is called 'presenteeism'. It is confirmed by a study ${ }^{(21)}$ of nurses who presented an index of lost productivity of up to $4.84 \%$. Presenteeism in the study ${ }^{(21)}$ was directly correlated with health treatment, the occurrence of absenteeism, and number of days off. For this reason, burnout needs to be identified, prevented, treated and reported ${ }^{(20)}$.

Significant statistical correlations show that residents experiencing high-stress presented a high level of Emotional Exhaustion and a high level of Depersonalization. A study(20) conducted with nurses also identified a positive statistical correlation between Stress and Emotional Exhaustion $(p<0.05 ; r=0.60)$ and Depersonalization $(p<0.05 ; r=0.40)$ subscales, and a negative statistical correlation with Professional Realization ( $p<0.05 ; r=-0.27)$.

We note that Emotional Exhaustion is the initial trait of burnout syndrome and is mainly perceived by individuals due to mental depletion. Researchers(22) report that physical and emotional exhaustion has been very noticeable in recent years. Such a fact occurs because some institutions ignore the suffering experienced by their employees and remain oblivious to reality. It is also related to the structure of industrial capitalism, whose conflicts between capital and labor, among other conflicts, de-motivate workers who then "sell" their work without an integral participation in the productive process ${ }^{(1)}$. For this reason, there is a need to value work and workers while in the situation of being the weakest link in the economic chain in the production and distribution of wealth(1).

Even though Emotional Exhaustion is an initial characteristic of burnout syndrome, it is important to note the high level of Depersonalization for two reasons. The first is that Depersonalization is considered an element specific to burnout syndrome when compared to the two other subscales. The second is that it reflects an attitude of estrangement and negative feelings in relation to the work per se, which affects both patients and the staff as well(13). A multicenter study ${ }^{(17)}$ highlights that aspects of hospital work such as improved relationships among patients, physicians and nursing professionals, as well as the involvement of nurses in decision-making, are associated with better outcomes for patients including a lower rate of mortality and greater satisfaction among patients.

In relation to Professional Realization, the studies previously mentioned indicate that professionals who experience high-stress present a low level of Professional Realization. However, this study does not report a significant correlation $(p=0.06, r=$ -0.44). Such a fact may be related to the specificity of the multidisciplinary residency, seen as a period of transition between academia and professional practice. Therefore, insecurity over the educational process can be minimized and feelings of efficiency and productivity can be strengthened over the period of residency. It may explain the results observed since the studied population was composed of residents from all the stages of the program.

Based on the analysis of statistical correlations, we verified that multidisciplinary residents experiencing high-stress presented some indication of burnout syndrome $(p=0.00 ; r=0.68)$. A study addressing medical students(23) identified significant statistical correlation $(p<0.05)$ between a high-stress and burnout syndrome. It shows that the presence of high- stress was responsible for the occurrence of the syndrome, that 
is, it was a predictor of burnout among multidisciplinary residents, confirming this study's initial hypothesis.

We note that burnout syndrome may occur from the beginning of professional activity, both during academic education and professional practice, or even in response to changes occurring in the work environment ${ }^{(24-25)}$. Also, this study corroborates data from the literature that stress in the long run may lead to burnout if ineffective strategies are used with negative consequences to individuals and organizations. For this reason, identifying stress and stressful situations enables the establishment of interventions to minimize its effects and prevent the occurrence of burnout syndrome in this population.

\section{Conclusion}

We observed the prevalence of low-stress among multidisciplinary residents and other populations analyzed in studies addressing burnout. Therefore, we believe that the residents have used effective coping strategies to minimize stress. Additionally, the presence of high-stress in other studies confirms that individuals evaluate stressors differently even if exposed to the same situations. It reinforces the theoretical frame of reference, according to which, the evaluation of stressors occurs at an individual level and varies according to one's cognitive, behavioral and emotional functions.

Additionally, the statistical correlations suggest that high-stress is a predictor of burnout syndrome, which confirmed the hypothesis of this study that multidisciplinary residents experiencing high-stress would also present burnout syndrome. This study's findings are in agreement with the literature concerning this subject, that is, the presence of stress in the long run can lead to burnout.

Even though we did not observe a significant correlation $(p>0.05)$ between high-stress and Professional Realization, we note this lack of correlation may be explained by the fact that residency programs represent a period of transition in the lives of students. We believe that the feeling of productivity and professional accomplishment is strengthened over the course of the residency based on the residents' experiences in the situations they face.

The correlations between high-stress and the Emotional Exhaustion and Depersonalization subscales on the MBI-HSS were statistically significant. These results indicate that the stress identified in the residents has led to Emotional Exhaustion and Depersonalization. Emotional Exhaustion is an initial sign of the syndrome and indicates special attention should be paid to prevent the future occurrence of this syndrome among these individuals.

In this context, we note the importance of similar studies in identifying the occurrence of burnout syndrome, analyzing its relationship with high-stress, and verifying the process of a cause-effect relationship, to strengthen the theoretical reference. Such studies can support future interventions directed to burnout syndrome and/or its prevention. These interventions should focus on the worker and the work environment seeking to balance the expectations of individuals and the organizations' demands.

It was, however, difficult to compare associations between high-stress and the occurrence of burnout with results from both Brazilian and international studies, due to the limited number of studies addressing this subject that use analytical methods. Studies have related perceived stress or overall stress with the MBIHSS subscales or with burnout syndrome but have not addressed any association between high/intense stress and/or level of stress with burnout syndrome, which is the main contribution of this study.

Thus, we suggest further analytical studies addressing stress and burnout among health workers with a view to produce scientific evidence concerning this subject. Additionally, we propose the development of intervention studies because this type of study enables the implementation of actions aimed to change the reality of workers.

\section{References}

1. Ornellas TCF, Monteiro MI. Historical, cultural and social aspects of labor. Rev Bras Enferm. 2006;59(4):552-5.

2. Jeong DJY, Kurcgant P. Factors of work dissatisfaction according to the perception of nurses of a university hospital. Rev Gaúcha Enferm. 2010;31(4):655-61.

3. Guido LA, Silva RM, Goulart CT, Kleinübing RE, Umann

J. Stress and coping among surgical unit nurses of a teaching hospital. Rev Rene. 2012;13(2):428-36.

4. Benevides-Pereira AMT. O Estado da Arte do Burnout no Brasil. Rev Eletron InterAçãoPsy. 2003;1(1):4-11.

5. Rosa SD, Lopes RE. Residência Multiprofissional em Saúde e Pós-Graduação Lato Sensu no Brasil: Apontamentos Históricos. Trab Educ Saúde. 2010;7(3):479-98.

6. Goulart CT, Silva RM, Bolzan MEO, Guido LA. Sociodemographic and academic profile of multiprofessional residents of a public university. Rev Rene. 2012;13(1):178-86. 
7. Nogueira-Martins LA. Residência Médica: estresse e crescimento. Psychiatry on-line Brazil. [periódico na Internet]; [acesso 15 jan 2009]; 1998;3(10). Disponível em: http://www.polbr.med.br/ano98/resid2.php

8. Fahrenkopf AM, Sectisch TC, Barger LK, Sharek PJ, Lewin D, Chiang VW, et al. Rates of medication errors among depressed and burnt out residents: prospective cohort study. BMJ. 2008;336(7642):488-91.

9. Franco GP, Barros ALBL, Nogueira-Martins LA, Zeitoun SS. Burnout in nursing residents. Rev Esc Enferm USP. 2011;45(1):12-8.

10. Paschoal TE, Tamayo A. Validation of the work stress scale. Estud psicol. 2004;9(1):45-52.

11. Lautert L. The professional fatigue: Empirical study with hospital nurses. Rev Gaúcha Enferm. 1997;18(2):133-44.

12. Hulley SB et al. Delineando a Pesquisa Clínica- Uma abordagem epidemiológica. Porto Alegre:Artmed; 2008. 13. Carlotto MS, Câmara SC. Psychometrics properties of Maslach Burnout Inventory in a multifunctional sample. Estud Psicol. (Campinas) 2007;24(3):325-32.

14. Conselho Nacional de Saúde. Resolução n. 196, de 10 de outubro de 1996. Dispõe sobre diretrizes e normas regulamentadoras de pesquisas envolvendo seres humanos. Bioética. 1996;4(2 Supl):15-25.

15. Stress among medical doctors working in public hospitals of the Ngaka Modiri Molema district (Mafikeng health region), North West province, South Africa S Afr J Psychiatry. 2010;18(2):42-6.

16. Trindade LL, Lautert L, Beck CLC. Coping mechanisms used by non-burned out and burned out workers in the Family health strategy. Rev. Latino-Am. Enfermagem. [periódico na Internet]; 2009; [acesso 17 set 2010]; 17(5):607-12. [7 telas]. Disponível em: http://www. scielo.br/scielo.php?script=sci_arttext\&pid=S0104$11692009000500002 \&$ Ing $=$ en.

http://dx.doi. org/10.1590/S0104-11692009000500002.

17. Aiken L, Sermeus W, Van den Heede K, Sloane DMS, Busse $R$, Mckee $M$, et al. Patient safety, satisfaction, and quality of hospital care: cross sectional surveys of nurses and patients in 12 countries in Europe and the United States. BMJ. [periódico na Internet]. mar 2012 [acesso 7 ago 2012 ]; 344(1717); [14 telas]. Disponível em: http://www.bmj.com/highwire/filestream/574655/ field_highwire_article_pdf/0.pdf

18. Aiken LH, Clarke SP, Sloane DM, Sochalski J, Silber

$\mathrm{JH}$. Hospital nurse staffing and patient mortality, nurse burnout, and job dissatisfaction. JAMA. 2002; 288(16): 1987-93.

19. Negeliskii C, Lautert L. Estresse laboral e capacidade para o trabalho de enfermeiros de um grupo hospitalar. Rev. Latino-Am. Enfermagem. [periódico na Internet]. maio-jun 2011 [acesso 7 ago 2012];19(3):[8 telas]. Disponível em: http://www.scielo.br/pdf/rlae/v19n3/ pt_21.pdf

20. Lorenz VR, Benatti MCC, Sabino MO. Burnout and stress among nurses in a university tertiary hospital. Rev. Latino-Am. Enfermagem. 2010;18(6):1084-91.

21. Umann J, Guido LA, Grazziano ES. Presenteeism in hospital nurses. Rev. Latino-Am. Enfermagem. [periódico na Internet]. 2012 [acesso 8 ago 2012];20(1):[08 telas]. Disponível em: http://www.scielo.br/pdf/rlae/ v20n1/pt_21.pdf

22. França SPS, Aniceto EVS, De Martino MMF. Predictors of Burnout syndrome in nurses in the prehospital emergency services. Acta Paul Enferm. 2012;25(1):68-73.

23. Santen SA, Holt DB, Kemp JD, Hemphill RR. Burnout in Medical Students: Examining the Prevalence and Associated Factors. South Med J. 2010;103(8):758-63.

24. Trindade LL, Lautert L, Beck CLC, Amestoy SC, Pires DEP Stress and Burnout Syndrome among workers of the Family Health team. Acta Paul Enferm. $2010 ; 23(5): 684-9$. 